\title{
Sarcoma of the Orbit pT4 TNM Finding v7
}

National Cancer Institute

\section{Source}

National Cancer Institute. Sarcoma of the Orbit PT 4 TNM Finding V7. NCI Thesaurus.

Code C88816.

Sarcoma of the orbit with tumor invasion of globe or periorbital structure, such as eyelids, temporal fossa, nasal cavity and paranasal sinuses, and/or central nervous system. (from AJCC 7th Ed.) 